\title{
CURRENT FORMS OF ASSESSMENT IN PRIMARY EDUCATION WITH A FOCUS ON FORMATIVE ASSESSMENT
}

\author{
Skutil $\mathrm{M}^{*}$ and Maněnová $\mathrm{M}$ \\ University of Hradec Králové, Faculty of Education, Institute of Primary and Preprimary \\ Education, Rokitanského 62, 50003 Hradec Králové, Czech Republic
}

\begin{abstract}
Assessment can be understood as an activity that pursues both the result as well as the process of achieving the goal, it monitors the conditions and means of achieving these goals and the activities of the pupil and teacher in the process of achieving goals. School assessment is a process that leads to determining the qualities and achievements showed by a pupil or a group of pupils; it is a systematic activity, i.e. prepared, organised and repeatedly performed, whereby the results are subject to revisions or corrections. Formative assessment is continuous feedback, where the learner obtains information in the learning process that compares the current situation with respect to the starting position and especially to the stated goal. The aim of our research was primarily to identify various forms of assessment at primary school and then to understand how teachers work with formative assessment in teaching practice. In view of the research objectives, a mixed research strategy was chosen. Within the quantitative survey, which focused on the assessment of various forms of assessment at school, a questionnaire of our own construction was used and was administered. The second step was implementing a qualitative survey, where semi-structured interviews were carried out focusing on the issue of format assessment in primary education. Results show that teachers often use alternative forms to the most common (summative) assessment in the form of pupils' portfolio, stamps, stickers, credits or letters. In terms of formative assessment, its contribution to pupils' development is appreciated as well as its greater informative value, but interestingly, many teachers use formative assessment without knowing that the chosen assessment method is known by this term.
\end{abstract}

Keywords: Primary education, school assessment, formative assessment, teaching methodology, methods of assessment

\section{Introduction}

Assessment is an integral and important part of our lives. It basically guides us every day. We perceive assessment on two levels. Either we are the assessors who assess, or we are assessed by others. We often do not even realise how important the role of assessment is in our lives. According to many studies, pupil assessment is ranked among the most difficult pedagogical activities. Especially in regard to novice teachers, this activity may be associated with uncertainty stemming from the lack of experience in the field (Kolář and Šikulová, 2009).

Assessment is an essential and integral part of learning and teaching because it provides feedback on how effective the learning process is (Black and William, 1998). Simultaneously, learning outcomes are an integral part of the assessment of schools as institutions. Teachers must involve a variety of 
assessment forms during the educational process. They are expected to be able to carry out both formative and summative assessments, i.e. they not only measure learning outcomes, but also the processes that take place within the learning process.

Assessment can take various forms. The assessment process can take more time and effort, depending on the assessment's objective and what is being assessed. Within the class, we assess learning because we need to know how effectively learners are learning to provide appropriate feedback. If facts are not remembered, if skills are not learned, if concepts are learned insufficiently, then a review of the learning process must follow. Without this step it is impossible to move further and build on the acquired curriculum. Such an approach not only guarantees adequate learning of the curriculum but, through relevant feedback, it supports further learning of pupils, which leads to success. At the same time, it can be used by teachers themselves in the assessment, which will improve teaching in the future (Petty, 2014).

School assessment is a pedagogical process that takes place in all directions. From pupil to pupil, from teacher to pupil and vice versa, between teachers towards each other and, last but not least, between school management and its staff. Therefore, it is a very interrelated relationship. However, school assessment is not random, but we encounter a very systematic concept. This article is focused on assessment between the pupil and the teacher. Generally speaking, school assessment is one of the means that a teacher can use to guide their pupils to manage and direct complex learning activities.

In this article we try to find the answer to the question, which selected forms of assessment in pedagogical practice with respect to formative assessment are being used in contemporary school education. We first define the concepts of assessment and school assessment, then we theoretically define types and forms of assessment. We also describe methodology of the survey, which is followed by interpretation and analysis of data and conclusions resulting from them.

\section{Assessment and school assessment}

In order to understand the assessment process correctly, the assessment concept itself needs to be defined first. Assessment is a comprehensive concept that covers a wide range of areas, processes and results. In relation to individual learning processes, the focus here is on identifying progress with regard to meeting goals. Teachers and pupils share the information needed to identify how learning and teaching can be adapted to improve it. The factors that influence whether students are more or less successful are also dependent on the environment in which learning takes place, on the school climate and also on the education system's general settings (Gardner, 2014).

The assessment concept is so extensive that it's basically unrealistic to determine its clear definition. Therefore, authors differ in their definitions. Slavík (1999) defines assessment as a comparison of "something" with "something", in which we distinguish "better" from "worse" and choose "better" or try to find a way to correct or at least improve "worse". Kolář and Šikulová (2009) add that assessment is an intellectually highly demanding skill that allows a person to differentiate important phenomena from unimportant phenomena and good from bad phenomena in the outside world through a subjective approach. Assessments are inseparable from values related to their awareness, discovery, highlighting, affirmation or questioning and criticism. Both authors definitions are in 
agreement in a fundamental matter, namely that the assessment principle is distinguishing better from worse, i.e. important from unimportant.

According to Kolár and Šikulová (2009), the act of assessment can be formulated as an activity, operation that:

- Pursues a goal (e.g. wants to influence a person's personality).

- Happens under very specific conditions (the specific nature of the teacher-student relationship).

- Is carried out by a certain means (verbal assessment, mark, awarding points...).

- Leads to a certain result (the pupil reacts in some way to the assessment, takes an internal position, accepts or does not accept the assessment).

We can find various pitfalls in assessment. Petty (2014) reports that an object, i.e. the assessment object is compared through a comparable object, or to an ideal pattern or standard. The question remains, who determines the model or standard on the assessment's basis.

Although assessment is often criticised for its inaccuracy, no teacher or society can do without it. However, a well-conducted assessment motivates, inspires and gives feedback to the individual's development, therefore providing space and opportunity for improvement (Petty, 2014).

School assessment is a specific type of assessment. Pasch (1991) mentions one fundamental principle that distinguishes school scores from all others. School assessment is systematic, so it's not a random and general assessment. Systematic assessment is based on the activities of a teacher who plans, thinks, organises, and carries out assessment on a regular basis. Assessment also serves as a feedback to the teacher concerning their pedagogical work, so the teacher not only assesses the pupils but also themselves.

School assessment has several important specifics (Slavin, 2000). One of them is systematicity. Each school has its own plan for assessing pupils which must be followed. Systematicity is only beneficial for pupils in terms of their awareness of the criteria on which their results are assessed. The teacher must be sure exactly how to assess in a certain situation and at what time intervals (Wyse, Wayward and Pandya, 2016). However, the teacher does not invent the criteria by themselves, they co-operate with so-called educational standards, which are formulated in various documents. Whether it is the Framework Educational Programme (2020) or the given school's educational plan.

Another specific feature is that assessment is de facto constantly occurring in the school environment. It is so related to teaching and education that there is no lesson whereby the teacher would not perform this activity (Murphy, 1999). All it takes is the teacher to smile, frown, say a simple yes, or simply nod their head. Furthermore, there is an assessment necessity parameter. On the one hand, it's a motivational element, and on the other hand, teaching could never bear the fruit without the teacher's feedback. Although self-assessment is important, it is not possible for us to just assess ourselves in life alone. Such a process would be biased and unprofessional. It is always necessary for the final assessment to be carried out by a person who is more experienced in the field than the person being assessed (Gardner, 2014). 
If the assessment is constant, then it must also be objective (Shepard, 2006). The teacher must note that it is not only the results, skills and knowledge that can be assessed, but the entire process which they perform with the pupil. How they were able to pass the subject to their students is also feedback for teachers. The analysis of this process is the motivation for pupils. Research has shown that assessment is needed and if the teacher ignores the results, the pupil becomes more passive and achieves results that are worse than prior to the test (Skutil, 2020).

\section{Assessment forms and types}

The assessment form is the external manifestation of the ongoing assessment process, i.e. the ways in which the teacher expresses the assessment's results. In recent years, the assessment function has overestimated the informative function at the expense of the formative function. This is a consequence of the transmissive concept of education. In this light, assessment issues were narrowed to testing and classification questions. Examination became the basic form of learning outcomes and grade was the main goal (Vališová and Kasíková, 2011).

We can distinguish two basic approaches to assessment - quantitative and qualitative (Kolár̆ and Šikulová, 2009).

- Quantitative assessment (summative) is mainly represented by classification. The problem is that this is a generalised information that does not usually take the range of the pupil's characteristics into account, which reduces its informative value. The mark is only a formal reflection of the expression of a very complex assessment process. For example, other quantitative assessment options include the number of points often used in tests, the percentual expression, or counting correct/wrong answers.

- Qualitative assessment (formative) should not only include information on the achieved learning outcomes, but also include pupils' attitudes and efforts. Its advantage is that it can reflect the pupil's individual progress better and provide more in-depth information concerning their strengths and weaknesses. Verbal assessment can be used as a continuous or final assessment. However, in addition to these positives, verbal assessment is challenging for teachers and there is a risk of slipping to cliché or using it as a retelling of the mark.

Formative assessment, corrective or feedback is mostly continuous, unlike a summative assessment. This concept was introduced in the early 1970s by people testing pupils such as B. Bloom, who believes that assessment is not just about measuring performance, but also about giving feedback, advice and seeking new ways to achieve the goal (Greger and Ježková, 2006). Formative assessment aims to identify mistakes in pupils' work and helps them overcome these difficulties and advises them on how to proceed. Its aim is to change the assessed individual first and only then, are they directed to changes in performance. Typical manifestation is verbal or numerical assessment by means of marks or points, but it should also be guided in the spirit of dialogue and instructions on how to change mistakes. Then, the pupil can understand this assessment as help (Black and Williams, 1998). This type of assessment can, as Slavík mentions below, occur in various forms of assessment. It can be formally assessed by means of e.g. verbal assessment as well as diagnostic tests, marks or selfassessment of the pupil. 


\section{Research methodology}

The research survey was carried out as a mixed research design. In line with current education trends and the pressure to use formative assessment in schools, we decided to conduct this research and understand how teachers currently use assessment in teaching practice, what motivations are for their choices and what different forms and types of assessment they use.

In the first phase of the research, video recordings of the individual teaching units were used and subsequently analysed. Interviews were conducted based on the results of these analyses, these were to discover the reasons for using the different types and forms of assessment in teaching and how teachers perceive the inclusion of formative assessment in their lessons.

\section{Research objectives}

The primary objective of the research was to identify various assessment methods and forms in primary schools. The secondary objective was to understand how teachers use formative assessment in their teaching. As a concretization of research objectives we can ask research questions: What is the importance attributed to the use of self-assessment of teachers at school? What is the opinion of teachers on the use of formative assessment in pedagogical practice?

\section{Research sample and its selection}

The research sample consisted of seven teachers from various primary schools in the Hradec Králové Region for video studies. A total of 32 teaching units were recorded and various subjects were intentionally chosen. The selection of schools and teachers can be characterised as a deliberate stratified selection (Gorard, 2001)., as the aim was to cover the widest possible range of schools.

The second phase, which was carried out by means of semi-structured interviews, and were focused on a deliberate selection of respondents, which followed the previous research phase. In this case, the research sample consisted of seven teachers from different types of primary education schools.

\section{Research method and data processing}

For the analysis of video studies (Goldman et al., 2007) the FI AS - Flanders' Interaction Analyses System (Flanders, 1970) method was used. A trained observer sits in the classroom and classifies the events into one of the many pre-defined categories of activities. However, they do not write the name of the activity but its code number. Coding proceeds according to precise rules, usually at threesecond intervals. The observation results are a sequence of numerical codes (up to 900 of them per lesson). Data is then processed, analysed and interpreted.

A semi-structured interview was used as a research method. Respondents were not informed in advance regarding the specific questions used in the interview. The only information given was the topic of "assessment at primary school", in order to prevent respondents from giving answers prepared in advance and therefore allowing for a more natural and immediate response. All interviews were recorded on a Dictaphone. Responses were subsequently rewritten, and non-verbal responses of respondents were recorded too (Silverman, 2013). In order to preserve anonymity, the first names of respondents were changed in the interview transcripts and the primary school where a respondent 
works was not identified. The constant comparison method was used for the analysis and for processing the obtained data. This method is suitable for analysing the selected research and most closely corresponds to the intention to compare the respondent' answers, therefore creating a more general opinion on the question (Yin, 2011).

\section{Research ethics}

The ethical aspect has already been outlined above. However, we should recall that, with regard to the possible identification of respondents, the respondents first names were changed in the interview transcripts and the primary school where the respondent works was not identified.

\section{Research results}

Video studies were carried out in the first quantitative phase. A categorised summary of forms and types of assessment that teachers use in their practice is created, based on the analysis of individual teaching units (Table 1).

Table 1: Overview of used assessment forms and types

\begin{tabular}{ll}
\hline Quantitative & Quantitative \\
\hline Credits & Formative assessment \\
\hline Letters & Verbal assessment \\
\hline Point scales & Portfolio \\
\hline Summative assessment (marks) & Pupil's self-assessment \\
\hline & Peer assessment \\
\hline
\end{tabular}

It turns out that teachers use a wide range of methods to assess a pupil's classroom performance. They justify this by trying to give the pupils feedback in the best possible way while respecting a pupil's individuality. Last but not least, an effort to support pupil learning and to motivate them to further efforts is also a motive.

Quantitative assessment in the form of grades is most often used. Although the trend within the Czech education system is gradually remove this assessment method, this quantifying approach still prevails. The reason is the relative simplicity of its use, but also the tradition of Czech education, when grading is required by parents as well as pupils. Traditionally, a five-grade scale 1-5 is used. However, teachers admit that the scale offered is insufficient. This fact also responds to the fact that many teachers use the standard classification variant with + and - in their practice. Therefore, there are signs like 3+, which means "better three" or 3-, meaning "worse three".

Credit rating is the absolute favourite. The term of credits is an umbrella for various stamps, stickers, emoticons, etc. Many teachers use this alternative to grades to mitigate the impact of a bad grade on pupils' psyche, but in principle it is the same system for assessing success or failure in a given activity. However, we admit that this system is sometimes more acceptable than a strict grading with grades, especially for younger schoolchildren.

The use of letters is another of a number of quantifying assessment options. It is a system that is commonly used in higher education assessment but is gradually beginning to be used at lower school 
levels too. Compared to traditional grades, A-F offers one more grade, giving you the option to refine performance ratings. This also corresponds to the teachers' requirement to be able to refine the assessment within the classification.

Point scales are another quantifying variant of the assessment. The most frequent variant is a ten-point point scale. While this allows for a more subtle assessment of pupil performance, the percentage conversion to grades is problematic. Teachers set a percentage of success for each grade, which makes assessment more transparent for pupils, but again, the result is a grade.

In terms of qualitative assessment types, verbal assessment is most often used. Most often in the form of teachers commenting on pupil performance and giving them feedback. This type of assessment does not yet show the full parameters of formative assessment, in other words, not all criteria are met to call this form of feedback formative. This is the most common, immediate way of expressing success or failure in the classroom, but usually combined with some basic shaping element to help pupils become aware of any shortcomings.

Formative assessment, as is commonly understood, is used less frequently than verbal assessment. However, it is true that it appears increasingly more often in Czech schools, as teachers are aware of the need to form feedback in order for pupils to be able to move further in their learning. Interestingly, in the analysis, teachers often do not know that they use formative assessment. In many cases, this is a subconscious activity, the need for teachers to work with pupils actively, and to create room for awareness and correction by the pupils themselves by means of relevant feedback.

One of the newer types of assessment in Czech schools is self-assessment. High-quality selfassessment is undoubtedly a very powerful tool, but relatively complex, so it requires longer preparation time. If learners are poorly prepared, they are likely to focus on the formal deficiencies of their activities rather than the actual processes that should be affected in the self-assessment. Selfassessment provides a new form of feedback. It creates an opportunity for dialogue between student and teacher on how learning is carried out. Student self-assessment is one of the strategies for developing self-reflection skills, pulling learners more into the learning process, helping them build an active and meaningful relationship to the content of education.

Peer assessment is also related to the above. However, this is a less frequently used option, which teaches pupils an objective assessment of the situation even when they assess individuals close to themselves. Proper implementation of peer assessment provides feedback to classmates as well as teaching the assessor to judge themselves impartially. In addition, teachers see this type of assessment as having the advantage that peer assessment is in many cases more seriously accepted than assessment from teachers.

A common standard of Czech schools is the use of portfolios. Larger pupils at primary schools have been creating their portfolios since the first grade. However, it is true that very few teachers use the portfolio to assess the development of pupils, i.e. they work with these materials to a very limited extent. Therefore, the portfolio represents a set of creations of pupils, and its assessment potential is very often unused. 
The second research phase was implemented through semi-structured interviews. In this case it was a qualitative survey, which focused on the most up-to-date area of assessment in Czech schools, which is formative assessment.

Teachers consider formative assessment to be effective. They support its inclusion in teaching, as it contains a wide range of means and methods that can be used for effective teaching. They emphasise that pupils should know what they are rated for and how they can work with their assessment results. In this context, they consider it essential to have a high degree of individualisation.

"I like it. When I can talk to my pupils about what they can and cannot do. Then they understand it better. But it's quite hard. It takes a lot of time. I understand it is needed, but I have to be prepared for it to be able to provide the feedback properly." (Monika)

In the classroom, teachers mostly use feedback, specifically asking pupils about reflective questions concerning the course. Here you can see the difference between verbal assessment and formative assessment. During the lessons, teachers most often use the question "How did you manage it?" "What can I help you with?" Or "Are you satisfied with your result?" Therefore, attention is paid to the performance component rather than the formative component. It is more about checking compliance with results rather than using it for further work.

Teachers also notice certain pitfalls regarding feedback and self-assessment that still need to be trained with the pupils. It becomes difficult for pupils to assess their classmates objectively and it tends to be judged on sympathy rather than performance and over or underestimating their classmates. Regarding self-assessment, it is more demanding for pupils than feedback. For example, if they are to assess their performance in testing, they are afraid to claim a good grade even though their performance was excellent. Teachers consider self-assessments as an integral part of formative assessment, especially from the perspective of pupil's personality development.

"Yeah, they like to assess themselves, some seem to overestimate, some underestimate. I do that I have those big smileys, I don't know if you saw them, for example, who liked it when the group worked, then they go to the smiley and then they should express themselves. "Why are you standing by this smiley?" They like to express themselves. Or I ask them, "If you look at how someone stands, do you think they stand right, someone would put someone differently"? And it's perfect when someone says: "No, maybe David, you were supposed to be at smiling face, you worked nicely." And that is for someone standing by the neutral face. And for the child, it is a great praise that they actually praise them, not the teacher, but others praise them." (Lucie)

Parents are a specific category in formative assessment. As mentioned above, the traditional approach at school is tied to the requirement of standard summative assessment. Many parents do not care what assessments take place during lessons, whether the pupil is able to assess in the lesson or whether they assess their classmates, but they care about the assessment the child brings home. Formative 
assessment expressed in verbal form is mostly considered to be incomprehensible and unclear by parents.

"Overall, I think parents look more at the grades anyway, whether we somehow assess it ourselves in that lesson or not, that parents don't care. And I would say they probably can't imagine the lesson and they only see those marks which they understand, because they had them at school." (Jana)

Teachers understand the complexity of formative assessment, so they continuously practice it with pupils, always using the chosen method more often to get used to it. Emphasis is placed on cooperation between the teacher and pupils as well as co-operation between pupils. The respondents are convinced that formative assessment can only be successfully applied in a classroom where a favourable social climate is set-up, where there is trust among the participants in the educational process. From their viewpoint it is not possible to separate the assessment as a separate category, it must always be understood in the context of the whole class.

\section{Conclusions}

School assessment is a complex process. Although teachers' work with assessment is at the forefront of their interest, there is still evidence that many teachers underestimate the impact of assessment on learning (Gardner et al., 2010). This is surprising to some extent, because the philosophy of assessment should be understood as a process whose fulfilment helps learners to improve their learning, as well as performing other tasks in the form of an external expression of the degree of success in achieving goals.

On the other hand, it is necessary to say that there is a growing interest from teachers in using assessment as an element supporting active learning. It is interesting in this context that if we ask teachers today about the issue of assessment, many will say that they do not feel well erudite in this area and that they do not even know what e.g. formative assessment actually is. However, paradoxically, they are actively using elements of formative assessment in the research observation of teaching units, although they are not aware of it themselves (e.g. Skutil, 2018).

Teachers use a wide variety of assessment types and forms. This is mainly because they need to capture different situations and achievements in school lessons. The second reason is that in society, and of course in schools, there is increasing pressure to use formative assessment as a way to further learning. Teachers consider formative assessment to be effective, especially in the form of reflective questions asked during class. This trend in assessment corresponds to a tendency towards a constructivist approach to education, which is based inherently on active interaction between teacher and pupil, and also on the pupil's responsibility to a certain degree. This is also the reason why qualitative forms of assessment are increasingly being promoted in education at the expense of quantitative forms of assessment.

Of course, we are aware that the conclusions presented have their limits and do not provide a comprehensive view of the issue. This is due to focus of the article, which deals with only one of the areas of assessment and also sue to unrepresentative research sample, which covers only a small 
spectrum of schools. Finally, the limit is the qualitative methodology itself, which by its nature can not generalize research findings.

This article focuses on standard assessment at school under normal conditions. However, with regard to the Covid-19 pandemic, we accept changes in the concept of the education system as well as changes in the way the school results are assessed. It is expected that online tools have become more important during pandemicand will continue to be used in education, even if in a limited scope. Further research is therefore offered in the field of digitization of assessment, or in the use of online tools in this area. It is likely that our further investigation will focus on this aspect of school assessment. Our research also suggests the need to pay due attention to the way teachers assess. The effects of different types and forms of assessment on student performance, but also on the formation of the personality of the assessed students, are not visible at first glance. They play an even more crucial role in building a relationship with learning, in understanding the need and consequences of education, but also in the question of the ability to self-assess and shape a person's self-concept. All this can be seen as further challenges for research, which in turn can contribute to a comprehensive understanding of the importance and impact of different types and forms of assessment on pupils in primary education.

\section{Acknowledgements}

The article was created with the financial support of the EU project: Improving the education of future teachers at the Faculty of Education, UHK, registration number: CZ.02.3.68/0.0/0.0/16_038/0006939 carried out at the Faculty of Education, University of Hradec Králové

\section{References}

Black, P. \& Wiliam, D. (1998). Assessment and classroom learning. Assessment in Education, 5(1), 774. https://doi.org/10.1080/0969595980050102

Flanders, N. A. (1970) Analysing Teaching Behaviour. London, Addison-Wesley.

Framework Education Programme for Basic Education (2020). Praha, The Ministry of Education, Youth and Sports of the Czech Republic.

Gardner, J. (2014). Assessment in Education. London, SAGE.

Gardner, J., Harlen, W., Hayward, L. \& Stobart, G. (2010). Developing Teacher Assessment. Glasgow, McGraw Hill.

Goldman, R., Pea, R., Barron, B. \& Derry, S. J. (Eds.). (2007). Video research in the learning sciences. Mahwah, NJ, Lawrence Erlbaum Associates.

Gorard, S. (2001). Quantitative methods in educational research. London, Continuum.

Greger, D. \& Ježková, V. (2006). Školní vzdělávání: zahraniční trendy a inspirace [School education: Trends and inspiration from abroad]. Praha, Karolinum.

Kolář, Z. \& Šikulová, R. (2009). Hodnocení žáků [Assessment of pupils], Grada, Praha.

Murphy, P. (ed.) (1999). Learner, learning \& assessment. London, SAGE.

Pasch, M. (1991). Teaching as Decision Making. New Jersey, Pearson Education.

Petty, G. (2014). Teaching today. Oxford, Oxford University Press.

Shepard, L.A. (2006). Classroom assessment. In BRENNAN, R. (2006). Educational measurement. Westport, CT: Praeger. 
Silverman, D. (2013). Doing Qualitative Research. London, Sage.

Skutil, M. (2020). Školní hodnocení z pohledu studentů učitelství 1.stupně ZŠ [School assessment from primary education student's point of view]. Praha, FF UK.

Skutil, M. (2018). Assessment as one of the key aspects of primary school education. In International Conference on Education and Development (ICED 2018). Paris, Atlantis press, 55-61. https://doi.org/10.2991/iced-18.2018.5

Slavík, J. (1999). Hodnocení v současné škole [Assessment in contemporary school], Portál, Praha.

Slavin, R.E. (2000). Educational Psychology. Boston, Ally\&Bacon.

Vališová, A. \& Kasíková, H. (2011). Pedagogika pro učitele [Pedagogy for teachers]. Grada, Praha. Wyse, D., Wayward, L. \& Pandya, J. (2016). Curriculum, Pedagogy and Assessment. London, SAGE. Yin, R. (2011). Qualitative Research from Start to Finish. New York \& London, The Guilford Press. 